\title{
Derechos y libertades y Estado de las Autonomías (1)
}

\author{
M. ${ }^{a}$ Isabel Álvarez Vélez \\ M. ${ }^{a}$ Fuencisla Alcón Yustas \\ Clara Martínez García
}

\begin{abstract}
Sumario: I. Introducción. - II. El alcance del Estado Autonómico en el marco de la Constitución Española de 1978. - III. Los derechos y libertades fundamentales como competencia estatal. -IV. La constitucionalidad de las declaraciones de derechos en los nuevos Estatutos de Autonomía.-V. Conclusiones: las reformas de los Estatutos ¿reforma constitucional encubierta?

Laburpena. Hitz gakoak. - Resumen. Palabras clave._Abstract. Keywords.
\end{abstract}

\section{Introducción}

Durante el proceso constituyente de 1978 hubo nuevamente que acometer uno de los temas más polémicos e intrincados de la historia política y constitucional española, la cuestión relativa a las autonomías territoriales, sofocadas durante el régimen jurídico de las Leyes Fundamentales, que establecía un poder político centralizado, de tendencias centrípetas. Esta situación llevó a que, durante la transición política, se desatara la fiebre regionalista. A pesar de ello, de alguna manera se pospuso el problema, aunque la Ley para la Reforma política de 4 de enero de 1977 establecía en el artículo 2.3, referente a la elección de los senadores, que serán elegidos «en representación de las entidades territoriales".

Tras las elecciones de 15 de junio de 1977, se planteó el problema regional, y se optó por generalizar los regímenes preautonómicos, intentando diluir, por una parte en un proceso general, el reconocimiento

(1) Este artículo es un recuerdo cariñoso al Prof. Dr. Javier Berriatúa con el que compartimos muchos momentos de conversaciones académicas acerca del nuevo Estado creado por la Constitución de 1978 y las cuestiones que en los ámbitos constitucional y administrativo surgirían con la implantación del modelo autonómico. 
primero de la Generalidad de Cataluña (restablecida por Decreto de septiembre de 1977) y después del Gobierno Vasco, evitando el impacto emocional que recordara lo sucedido durante la Segunda República. Además, se intentó de esta manera contentar las aspiraciones de la clase política de las diversas regiones españolas que reivindicaban el reconocimiento regional (2). Así en el plazo de un año, desde septiembre de 1977 hasta octubre de 1978, se generalizaron mediante la fórmula del Decreto Ley en todo el territorio los regímenes preautonómicos (3).

Pero, a diferencia de la Constitución de 1931, el texto constitucional de 1978 no ofrece una definición concreta de la forma de Estado que crea, puesto que la denominación de Estado Autonómico fue aportada por la doctrina, aunque sí proclama los tres principios de los que debe desprenderse la configuración territorial del Estado español: unidad, autonomía y solidaridad, como veremos más adelante.

El Estado de las Autonomías se regula en el Título VIII de la Constitución. Si algo caracteriza a este título es el "consenso" entre las fuerzas políticas del que surgió una innovadora organización territorial, aunque el resultado, según opinión unánime de la doctrina, es un texto «con evidentes lagunas, imprecisiones y ambigüedades, necesarias quizá desde la perspectiva política, pero fuente indudable de tensiones y conflictos a la hora de su interpretación jurídica» (4). Bien es cierto que esas imprecisiones y esas ambigüedades permitieron que la nueva construcción del Estado fuera aceptada con un amplio grado de generalidad (5) y que poco a poco, el Título VIII de la Constitución dejara de ser una «enorme disposición transitoria que debía ser llenada de contenido a medida que se fueran cumpliendo sus previsiones" (6). Y también es cierto que existía una urgencia en hacerlo con la finalidad de que se diera satisfacción a las ansias nacionalistas de determinadas zonas del

(2) Antes de aprobarse la Constitución se llegaron a reconocer trece distintos entes preautonómicos, Cataluña, 29 septiembre 1977; País Vasco, 4 enero 1978; Galicia, 16 marzo 1978; Aragón, 17 marzo 1978; Valencia, 17 marzo 1978; Canarias, 17 marzo 1978; Andalucía, 27 abril 1978; Baleares, 13 junio 1978; Extremadura, 13 junio 1978; Castilla- León, 13 junio 1978; Asturias, 27 septiembre 1978; Murcia, 27 septiembre 1978; Región Castellano- Manchega, 31 octubre 1978. Vid. ESTEBAN, J. DE y LÓPEZ GUERRA, L., El régimen constitucional español, Vol. II, 1978, p. 335.

(3) Esta generalización, aunque motivada por las razones que señalamos, suscita algunas críticas. Así señala MARTín RETORTILLO que tuvieron una cierta "dosis de folklorismo", puesto que muchas Comunidades dedicaron sus primeras actuaciones al establecimiento de un himno, una bandera, fiestas de la Comunidad... Vid. MARTíN RETORTILLO, S., «Estudio Preliminar», en MARTÍN-RETORTILLO BAQUER, S. y otros, Pasado, presente y futuro de las Comunidades Autónomas, Madrid, 1989, p. 29.

(4) Cfr. ALONSO DE ANTONIO, J. A., El Estado Autonómico y el principio de solidaridad como colaboración legislativa, Vol. I, Madrid, 1986, p. 272.

(5) MARTíN-RETORTILLO, S., op. cit., p. 24.

(6) Cfr. TORRES MURO, I., Los Estatutos de Autonomía, Madrid, 1999, p. 18. 
Estado, evitando a su vez que éstas quedaran al margen del nuevo orden constitucional.

La respuesta de la Constitución consistió en la creación de un modelo territorial abierto, que dejaba en manos del legislador ordinario el establecimiento de los elementos definitivos del sistema. El objeto perseguido consistía en la transformación de un Estado unitario en un Estado descentralizado, mediante la instauración de unos Entes superiores autonómicos. Así, frente al Estado federal de corte tradicional, la ordenación territorial de 1978 está fundamentada en la aprobación postconstitucional de los Estatutos de Autonomía, norma institucional básica de cada Comunidad Autónoma, que se integra en el ordenamiento estatal, ya que se aprueban por Ley Orgánica (artículo 81.1 de la Constitución), y que el Estado reconoce y ampara como parte de su ordenamiento jurídico (artículo 147.1 de la Constitución). Por el contrario, un Estado federal, modelo del que ya había huido la Constitución de la Segunda República, se organiza a través de un pacto de entidades preexistentes que ostentan poder constituyente originario, lo que les permite otorgarse su propia Constitución.

En cuanto al aspecto material, el artículo 147.2 de la Constitución señala el contenido mínimo obligatorio de los Estatutos.

«Los Estatutos de Autonomía deberán contener:

a) La denominación de la Comunidad que mejor corresponda a su identidad histórica.

b) La delimitación de su territorio.

c) La denominación, organización y sede de las instituciones autónomas propias.

d) Las competencias asumidas dentro del marco establecido en la Constitución y las bases para el traspaso de los servicios correspondientes a las mismas».

Además, el Estatuto ha de incluir el procedimiento para su reforma, aunque en ningún caso podrá suprimirse la aprobación final en las Cortes Generales, como Ley Orgánica (artículo 147. 3 de la Constitución).

Vamos a centrar nuestro estudio en tres cuestiones. En primer lugar, abordaremos un análisis del primer desarrollo del Estado Autonómico. Posteriormente, analizaremos el aspecto competencial que presentan los derechos y libertades fundamentales al ser reserva de Ley Orgánica y, finalmente, estudiaremos el contenido de los Estatutos de Autonomía aprobados a partir del 2006 con la inclusión de una parte dogmática en todos ellos, para terminar realizando una breves conclusiones acerca del futuro del Estado Autonómico. 


\section{El alcance del Estado Autonómico en el marco de la Constitución Española de 1978}

Superada la etapa inicial de aprobación de los Estatutos (1979 a 1983), caracterizada por un distanciamiento cada vez mayor entre las Comunidades de uno y otro tipo, se ha procedido, sobre la base de los Acuerdos Autonómicos suscritos el 28 de febrero de 1992, a las consiguientes reformas estatutarias según los procedimientos que los mismos Estatutos regulan (7) y en los casos de aquellas Comunidades Autónomas que accedieron por la vía del artículo 143 de la Constitución.

Respecto de aquella primera etapa, los Acuerdos Autonómicos de 31 de julio de 1981 generalizaron la autonomía a todos los territorios del Estado, de manera que todos los entes autonómicos surgidos de aquella primera etapa compartían su configuración como autonomías políticas, si bien el nivel competencial no era el mismo en cada caso (8).

La etapa que comienza una vez transcurridos los cinco años previstos en el artículo 148 de la Constitución, impulsada por los Acuerdos Autonómicos de 1992 recogidos en la Ley Orgánica 9/1992, de 23 de diciembre (9) supone dar un paso más en el avance descentralizador que se prescribe en el texto de la Constitución (10). Si la etapa anterior se caracterizó por sentar las bases del modelo, generalizando la autonomía política de los

(7) Sobre el alcance de los Acuerdos, vid. HERNÁNDEZ LAFUENTE, A. y GONZÁLEZ GARCÍA, M. A. Octubre de 1992-marzo de 1993. "Los Acuerdos Autonómicos de 28 de febrero de 1992", en Documentación Administrativa, núm. 232-233, pp. 135 y ss. Han reformado sus Estatutos las siguientes Comunidades: Andalucía por Ley Orgánica 7/2007, de 19 de marzo; Aragón por las Leyes Orgánicas 6/1994, de 24 de marzo, 5/1996, de 30 de diciembre, y 5/2007 de 20 de abril; Principado de Asturias por la Leyes Orgánicas 3/1991, de 13 de marzo, y 1/1994, de 24 de marzo; Illes Balears por las Leyes Orgánicas 9/1994, de 24 de marzo, 3/1999, de 8 de enero, y 1/2007, de 28 de febrero; Canarias por la Ley Orgánica 4/1996, de 30 de diciembre; Cantabria por las Leyes Orgánicas 7/1991, de 13 de marzo, 2/1994, de 24 de marzo de 1994, y 11/1998, de 30 de diciembre; Castilla- La Mancha por las Leyes Orgánicas 7/1994, de 24 de marzo, y 3/1997, de 3 de julio; Castilla y León por las Leyes Orgánicas 11/1994, de 24 marzo y 4/1999, de 8 de enero, y 14/2007, de 30 de noviembre; Cataluña por la Ley Orgánica 6/2006, de 19 de junio; Comunidad de Madrid por las Leyes Orgánicas 2/1991, de 13 de marzo, 10/1994, de 24 de marzo y 5/1998, de 7 de julio; Comunidad Valenciana por la Leyes Orgánicas 4/1991, de 13 de marzo y 1/2006 de 10 de abril; La Rioja por las Leyes Orgánicas 3/1994, de 24 de marzo, y 2/1999, de 7 de enero; Extremadura por las Leyes Orgánicas 5/1991, de 13 de marzo, 8/1994, de 24 de marzo, y 12/1999, de 6 de mayo; Región de Murcia por las Leyes Orgánicas 1/1991, de 13 de marzo, 4/1994, de 24 de marzo, y 1/1998, de 15 de junio; Navarra por la Ley Orgánica 1/2001, de 26 de marzo.

(8) ARAGÓN, M., "La construcción del Estado autonómico», iustel.com, Revista General de Derecho Administrativo, marzo de 2006, pp. 1-24. Según este autor, las características del modelo resultante eran: la generalización de la autonomía territorial; la caracterización de esa autonomía como política, la diferenciación competencial y estatutaria en función de la vía seguida para el acceso a la autonomía (p. 9).

(9) BOE núm. 308 de 24/12/1992, de transferencia de competencias a Comunidades Autónomas que accedieron a la autonomía por la vía del artículo 143 de la Constitución.

(10) Vid. ARCE JANÁRIZ, A., "La reforma de los Estatutos de Autonomía pactada en los Acuerdos Autonómicos de 1992», RVAP núm. 40, 1994, pp. 9-32. 
diecisiete territorios, en esta segunda etapa el objetivo fue acercar los niveles competenciales de aquellas Comunidades Autónomas que no alcanzaban los de aquellas que tenían niveles competenciales superiores.

En todos los casos en que esas reformas se han llevado a cabo, se ha procedido a ampliar, dentro del ámbito de los artículos 148 y 149 de la Constitución, las competencias, teniendo en cuenta la idea previa de la que se partía, en virtud de la cual la autonomía se implanta de forma evolutiva y sobre la base de un modelo flexible. Se ha escrito mucho sobre la posibilidad de que la meta a la que se ha de llegar sea al establecimiento en España de un Estado federal (11), situación que sólo sería posible mediante la modificación del texto constitucional (12). Grave sería en este punto que la transformación se produjera, como en cierta medida parece que se está haciendo, por vía normativa secundaria, sin alterar el contenido de la Constitución, dando lugar a una "mutación del texto constitucional» (13). Lo cierto es que en todos los supuestos de reformas estatutarias que se han producido en la tercera etapa de reformas, el impulso obedece a un objetivo hasta el momento común que es el de incrementar las competencias de las Comunidades Autónomas, restringiendo las del Estado, especialmente en el caso de las competencias compartidas (14). En todo caso, como ha señalado ARGULLOL, "el nuevo proceso de reformas estatutarias en curso presenta características muy distintas de las anteriores" porque esta "reforma pretende identificar nuevos ámbitos competenciales y una diferente definición, al menos parcialmente, del régimen jurídico de competencias» (15).

Este proceso debe enmarcarse en lo dispuesto por la Constitución, norma de la que todas las demás, incluyendo los Estatutos de Autonomía, traen causa, en la que junto con el principio dispositivo, motor indiscutible de las reformas brevemente referidas, coexisten en equilibrio inestable los principios de unidad, igualdad y solidaridad. Además, no debemos olvidar el papel más que destacado que el Tribunal Constitucional ha desempeñado a lo largo de todo este proceso y previsiblemente ocupará al menos en el futuro más inmediato.

(11) Véanse en esta línea los razonamientos de DE OTTO, I., Estudios sobre Derecho estatal y autonómico, Madrid, 1986.

(12) Así ha sucedido en el caso de la reforma constitucional belga de 1994 en la que la organización territorial es federal, aunque la base lingüística y la complejidad del reparto competencial no parecen el mejor ejemplo a seguir. Vid. ÁLVAREZ VÉLEZ, M. I. y ALCÓN YUSTAS, M. F., Las Constituciones de los quince Estados de la Unión Europea, Textos y comentarios, Madrid, 1996, pp. 145- 146.

(13) Cfr. AJA, E., Informe Comunidades Autónomas 1994, Madrid, 1994. p. 32.

(14) En este sentido, BIGLINO CAMPOS, P., «Reforma de la Constitución, reforma de los Estatutos de Autonomía y configuración constitucional del orden de competencias", Revista de las Cortes Generales, núm. 65, 2007, pp. 8-28.

(15) ARGULLOL MURGADAS, E., "La reforma estatutaria: una primera aproximación", Revista de Administración Pública, núm. 174, septiembre-diciembre, 2007, p. 200. 
La Constitución española de 1978, en su artículo 2 establece tres principios fundamentales en la organización territorial del Estado: "La Constitución se fundamenta en la indisoluble unidad de la Nación Española, patria común e indivisible de todos los españoles y reconoce y garantiza el derecho a la autonomía de las nacionalidades y regiones que la integran y la solidaridad entre todas ellas". Unidad, derecho a la autonomía y solidaridad son los tres pilares sobre los que se asienta el Estado creado a partir de la vigencia de la Constitución.

El principio de unidad de la Nación Española, a la cual denomina además patria común e indivisible de todos los españoles, aparece vinculada a una única soberanía del pueblo español como proclama el artículo 1.2 de la Constitución. Esta concepción supone la negación del pretendido derecho a la autodeterminación, que sólo sería viable mediante la reforma del texto constitucional (16). La coexistencia de varios ordenamientos jurídicos en un mismo territorio no significa una ruptura del principio de unidad, sino al contrario, reafirma el valor supremo de la Constitución y de los Estatutos de Autonomía, normas estatales, en cada una de las Comunidades Autónomas. Como señala GARCÍA DE ENTERRÍA «la Constitución es el supraordenamiento y en él se articulan el ordenamiento estatal stricto sensu y el autonómico, entendidos como subsistemas por debajo de la norma suprema común» (17).

La unidad de la Nación Española se convierte en el presupuesto de la autonomía, puesto que la soberanía nacional reside en el pueblo español (artículo 1.2 de la Constitución) y la Nación proclama la Constitución en "uso de su soberanía» (Preámbulo de la Constitución). Así lo ha considerado el Tribunal Constitucional desde sus primeras Sentencias: "La Constitución (artículos 1 y 2) parte de la unidad de la Nación española que se constituye en Estado Social y Democrático de Derecho, cuyos poderes emanan del pueblo español en el que reside la soberanía nacional. Pero los órganos generales del Estado no ejercen la totalidad del poder público, porque la Constitución prevé, con arreglo a una división vertical de poderes, la participación en el ejercicio del poder de entidades territoriales de distinto rango, tal como se expresa en el artículo 137 de la Constitución; y continua el Tribunal que dado que «cada organización territorial dotada de autonomía es una parte del todo, en ningún caso el principio de autonomía puede oponerse al de unidad, sino que es dentro de esta donde alcanza su verdadero sentido, como expresa el artículo 2 de la Constitución» (18).

(16) Vid., por todos los autores, SÁNCHEZ AGESTA, L., El sistema político de la Constitución española de 1978, Madrid, 1985, p. 346.

(17) GARCíA DE ENTERRÍA, E. y FERNÁNDEZ, T. R., Curso de Derecho Administrativo (I), Madrid, 2000, p. 284.

(18) STC 4/1981, de 2 de febrero. 
Además, los artículos 138.2 y 139 de la Constitución representan la aplicación del principio de igualdad a la organización territorial, y por tanto son manifestaciones de la unidad del Estado. La articulación jurídica de estos preceptos constitucionales con la diversidad normativa de las distintas Comunidades Autónomas, debe encontrarse en el equilibrio entre los principios de igualdad, unidad y de autonomía; los dos primeros, constituyen el marco estatal que asegura la igualdad de los españoles que gozan de "los mismos derechos y obligaciones en cualquier parte del territorio del Estado" (artículo 139.1 de la Constitución), "de la libertad de circulación de personas y bienes por todo el territorio nacional» (artículo 139.2 de la Constitución), garantizando la interdicción de que los Estatutos de las Comunidades Autónomas impliquen privilegios económicos o sociales (artículo 138.2 de la Constitución), pero la autonomía es pluralidad, y exige la convivencia de ordenamientos jurídicos dispares en el seno del Estado. Por ello, el Tribunal Constitucional declaró que atentan al principio de igualdad aquellas decisiones que impliquen «una diferencia no justificada o que no tienen justificación razonable alguna» (19).

Evidentemente, un sistema de organización territorial que, como el nuestro, lleva a cabo una distribución del poder político entre entes dotados de potestad legislativa propia, implica necesariamente un ordenamiento jurídico complejo. Junto a normas vigentes para toda España, hay otras cuya vigencia está limitada al territorio de la correspondiente Comunidad Autónoma.

En relación a la igualdad de derechos de las Comunidades Autónomas se ha manifestado el Tribunal Constitucional señalando que «el régimen autonómico se caracteriza por un equilibrio entre la homogeneidad y diversidad del status jurídico público de las Entidades territoriales que lo integran", añadiendo que "sin la primera, no habría unidad ni integración en el conjunto estatal; sin la segunda, no existiría verdadera pluralidad ni capacidad de autogobierno, notas que caracterizan al Estado de las Autonomías» (20).

En relación con el artículo 139.1 de la Constitución, el Tribunal Constitucional ha declarado que este precepto «no exige un tratamiento jurídico uniforme de los derechos y deberes de los ciudadanos en todo tipo de materias y en todo el territorio del Estado, lo que sería frontalmente incompatible con la autonomía, sino a lo sumo (...) se refiere a una igualdad de posiciones jurídicas fundamentales» (21).

(19) STC 42/1981, de 22 de diciembre.

(20) STC 76/1983, de 5 de agosto.

(21) STC 37/1987, de 16 de marzo. 
El principio de autonomía de las nacionalidades que integran la nación española, parece que se contrapone al principio de unidad, pero no es así. La diferencia entre ambos consiste en que el principio de autonomía deriva de la Constitución, mientras que ésta deriva del principio de unidad (vid. artículo 149.3 de la Constitución). Así el Estado español es un Estado asentado sobre la Nación española, derecho originario, y el derecho a la autonomía es un derecho derivado de la Constitución y por tanto, subordinado a la soberanía nacional (22). En este mismo sentido, el reconocimiento constitucional, plasmado en los Estatutos de Autonomía, supone dotar a éstos de un carácter de norma subordinada al texto constitucional, y al margen de apreciaciones políticas, jurídicamente es indefendible otorgar a los Estatutos rango similar al de la Constitución. Así, en palabras del Tribunal Constitucional, "el Estatuto de Autonomía, al igual que el resto del ordenamiento jurídico, debe ser interpretado de acuerdo con la Constitución» (23). Polémico fue el empleo del término nacionalidades en este artículo 2 de la Constitución. Como explica ALZAGA el término fue introducido por los grupos nacionalistas catalanes, siendo aceptado por el resto de las fuerzas políticas como una fórmula de compromiso, que suponía la renuncia de aquellos a reivindicar en un futuro la formación de un Estado propio (24).

Este segundo principio que recoge el artículo 2 de la Constitución, el de autonomía, es utilizado por el texto constitucional en diversos sentidos. El artículo 137 garantiza la autonomía de Municipios, Provincias y Comunidades Autónomas, "para la gestión de sus respectivos intereses", pero no puede equipararse la autonomía de la que gozan Municipios y Provincias, con la que ostentan las Comunidades Autónomas.

Frente a la autonomía de los entes locales, las Comunidades se alzan como entes superiores, cuya autonomía conlleva el disfrute de la más alta potestad que pueda ser atribuida al poder político, la de dictar normas con rango de Ley, que sólo serán controlables por el Tribunal Constitucional, a través de los consiguientes procesos de inconstitucionalidad (artículo 153 a) de la Constitución). Por ello, la Constitución prevé para

(22) ALZAGA VILLAAMIL, O., La Constitución española de 1978 (Comentario sistemático), Madrid, 1978, pp. 101-102.

(23) STC 18/1982, de 4 de mayo.

(24) ALZAGA VILLAAMIL, O., op. cit., p. 103. Señala por su parte ALONSO DE ANTONIO que «es posible que en la mente de los constituyentes estuviera presente la idea de limitar la autonomía plena a Cataluña, País Vasco y, de paso, Galicia, entendiéndose como nacionalidades históricas, lo que explicaría, por lo demás el privilegiado régimen de acceso a la autonomía previsto en la Disposición transitoria segunda de la Constitución». Vid. ALONSO DE ANTONIO, J. A., op. cit., p. 293. Sobre el concepto de nacionalidades, vid. ALCÓN YUSTAS, M. ${ }^{a}$ F., "Nación o Nacionalidades. Una aproximación al concepto político-constitucional del término Nación», en RUIZ-RICO RUIZ, G., La reforma de los Estatutos de Autonomía, Valencia 2006, pp. 153-168. 
las Comunidades Autónomas una autonomía de naturaleza superior, que se constituye en derecho ejercitable por "nacionalidades y regiones" (artículo 2 de la Constitución). Y, aunque no reconoce otra soberanía que la de la Nación española, se reconoce la existencia de unos territorios españoles con características específicas, anteriores a la promulgación del texto constitucional.

Se proclama finalmente, un tercer principio, consecuencia de los otros dos, el de solidaridad, que se configura como "principio estructural básico de nuestra forma de Estado" (25).

Así el artículo 138.1 de la Constitución reconoce que «el Estado garantiza la realización efectiva del principio de solidaridad, consagrado en el artículo 2, velando por el establecimiento de un equilibrio económico, adecuado y justo entre las diversas partes del territorio español». Este principio, de claras interpretaciones sociales y económicas, supone el respeto de las Comunidades, de sus propias identidades y conlleva la consecuencia de integrar una comunidad superior que es la nación española. Es evidente que el principio es ciertamente ambiguo y complicado de realización, puesto que supone que, sin desconocer la existencia e importancia de los intereses propios de cada Comunidad, es superior el interés general, el bienestar común de todos ciudadanos, que debe ser debidamente respetado por el actuar de las Comunidades (26). Pero la dificultad de su concreción no puede llevar a concluir su inaplicabilidad. Antes bien, el Informe del Consejo de Estado sobre las modificaciones de la Constitución en relación al principio de solidaridad señala que «con independencia del contenido específico que en las distintas ramas del ordenamiento se le atribuye, este término no se utiliza en el lenguaje jurídico para designar sentimientos subjetivos, individuales o colectivos, sino un principio objetivo del que dimanan deberes concretos, cuya observancia puede ser exigida y asegurada con los medios que el Derecho ofrece» (27). Y añade que pese a las referencias del texto constitucional a dicho principio no concretan el alcance y contenido de éste, el Consejo de Estado sostiene que una interpretación correcta del artículo 138.2 de la Constitución impone que el Estado (como poder central) garantice la solidaridad y «su realización efectiva», de modo que aquél fomente los comportamientos solidarios de las Comunidades Autónomas y contribuya a combatir los que no lo sean.

En línea con lo sentado por el Tribunal Constitucional, TORNOS MAS entiende que "lo que puede exigirse es un nivel de prestaciones homo-

(25) TAJADURA TEJADA, J., "Reformas territoriales y Estado social», Sistema, núm. 1296, 2007, pp. 49 a 73.

(26) ALONSO DE ANTONIO, J. A., op. cit., p. 379.

(27) Informe del Consejo de Estado sobre la Reforma de la Constitución, febrero de 2006, p. 188. 
géneo garantizado por el legislador estatal» (28), si bien según el nivel de eficacia real de cada Administración los ciudadanos destinatarios de su acción disfrutarán de mayores o menores, mejores o peores servicios. Y ello no es contrario a la solidaridad sino consustancial a un Estado Autonómico que comprende también lo diverso.

Por su parte, elTribunal Constitucional ha manifestado que el principio de solidaridad "exige un comportamiento leal y la aceptación del sistema de distribución territorial del poder, procurando su continuación» (29). Así, a través de la jurisprudencia del Tribunal Constitucional, se han vinculado al principio de solidaridad, los deberes de cooperación (30), el auxilio recíproco (31) y el principio de lealtad (32). Respecto de ellos, el Consejo de Estado estima que sería conveniente reflexionar acerca de la conveniencia de consagrar explícitamente en la Constitución el deber de cooperación y colaboración, por considerar que en esta fase de vigencia de nuevos Estatutos probablemente sean las fórmulas que de él derivan las más adecuadas para reforzar el modelo autonómico.

El papel que ha desempeñado el Tribunal Constitucional ha sido determinante del modelo de descentralización territorial que actualmente tenemos, al haber concretado y definido aspectos que conscientemente quedaron sin determinar en el texto constitucional. Dicho papel es, incluso, a juicio de algunos, inadecuado por excesivo (33), de modo que sería preferible dejar delimitado el modelo de distribución territorial en el propio texto constitucional, tal como ha sugerido el Consejo de Estado en el Informe sobre modificaciones de la Constitución española (34), por encontrar que esta opción no sólo es jurídicamente más simple sino también políticamente menos traumática (35). Algún autor (TAJADURA) incluso ha planteado y detallado una posible articulación del control previo de constitucionalidad limitado a las reformas estatutarias, evitando complicaciones especialmente de índole política al evitar obligar al Tribunal

(28) TORNOS MAS, J., "La reforma estatutaria. Un debate marcado por la posición constitucional de los Estatutos de Autonomía», iustel.com, Revista General de Derecho administrativo, núm. 12, junio de 2006, pp. 1-15.

(29) STC 135/1992, de 5 de octubre. En el mismo sentido, STC 64/1990, de 5 de abril.

(30) STC 152/1988, de 20 de julio.

(31) SSTC 236/1991, de 12 de diciembre, y 51/1993, de 11 de febrero.

(32) STC $64 / 1990$, de 5 de abril, entre otras.

(33) Así, BIGLINO CAMPOS, P., «Reforma de la Constitución...», op. cit., p. 23.

(34) Página 143 del Informe.

(35) ARGULLOL MURGADAS ha señalado que "plantear una reforma constitucional como etapa previa a la modificación de los estatutos es una opción de política legislativa que ofrece ventajas, como asimismo algunos inconvenientes, pero no es una necesidad insoslayable», op. cit., p. 206. 
Constitucional a pronunciarse sobre cuestiones que han sido sometidas a referéndum (36).

También en cuanto a los derechos fundamentales, como se desarrolla a continuación, ha señalado el Tribunal Constitucional que las Leyes Orgánicas no impiden que sobre algunas de sus materias pueda haber legislación complementaria de las Comunidades Autónomas, siempre que éstas tengan competencias sobre ella. Por consiguiente, en la regulación de los derechos fundamentales, concluye ARAGÓN basándose en la jurisprudencia constitucional, "el ámbito de la reserva de Ley Orgánica (artículo 81.1 de la Constitución) no es coextenso a las competencias atribuidas al Estado, y, en cuanto a los derechos fundamentales, no supone, por principio, la reserva al Estado de una materia, sino de la regulación de un segmento nuclear de la misma» (37). En similar sentido, el Consejo de Estado afirma que hablar de igualdad en el ejercicio de derechos fundamentales a la vista de los contenidos de los Estatutos de Autonomía resulta superfluo «porque todos los entes dotados de autonomía, como todos los órganos del Estado, están vinculados por estos derechos y su regulación y desarrollo, que ha de asegurar la igualdad en su disfrute, están reservados a las Cortes Generales» (38). Más contundente resulta AGUADO al mostrar su opinión contraria a la inclusión de derechos en la norma estatutaria, por resultar contraria a lo que «resulta propio de un instrumento regulador de la organización del gobierno (estructura y competencias) de un ente territorial con autonomía política, que constituye la razón de su previsión constitucional» (39).

\section{Los derechos y libertades fundamentales como competencia estatal}

La decisión constituyente de introducir en el sistema de fuentes la Ley Orgánica fue recibida por la doctrina tanto con interés, como con incertidumbre. Por una parte, los antecedentes en el Derecho español parecían aproximar el nuevo tipo de Ley a la regulación de órganos del Estado, como la Ley Orgánica del Poder Judicial de 1970 o la Ley del Consejo de Estado de 1945. Además, entre las Leyes Fundamentales dictadas durante

(36) Vid.TAJADURA TEJADA, J., "Reformas estatutarias y control previo de constitucionalidad", Revista Española de Derecho Administrativo, núm. 132, 2006, pp. 645-660.

(37) ARAGÓN, M., "La construcción...», op. cit., p. 15.

(38) Informe del Consejo de Estado sobre la reforma de la Constitución, febrero de 2006, p. 196.

(39) AGUADO RENEDO, C., "De nuevo sobre la naturaleza jurídica del estatuto de Autonomía con motivo de los procesos de reforma", Asamblea. Revista parlamentaria de la Asamblea de Madrid, núm. 17, 2007, pp. 283 a 306. 
el régimen del General Franco, tan próximo en el tiempo al momento constituyente, se incluía la Ley Orgánica del Estado de 10 de enero de 1967 (40).

Por otro lado, los constituyentes españoles disponían, para inspirarse, del modelo establecido en la Constitución francesa que, como es sabido, regula, en el artículo 46, las Leyes a las que la Constitución confiere el carácter de orgánicas, para cuya aprobación se establece un procedimiento agravado que el mismo artículo precisa, instituyéndose así un tipo de norma superior al resto de las Leyes (41).

En el texto constitucional español las Leyes Orgánicas estuvieron presentes desde el Anteproyecto, que contemplaba, en el apartado 1 del artículo 73, la creación de dichas Leyes, con la siguiente redacción: "Son Leyes Orgánicas las relativas al desarrollo de los Títulos I y II de la Constitución, a la organización de las instituciones centrales del Estado, las que aprueben los Estatutos de Autonomía y el régimen electoral general» (42).

A lo largo del proceso constituyente el contenido de este precepto no se modificó sustancialmente. En el informe de la Ponencia se introdujo algún cambio en el precepto, convertido en artículo 74. Por una parte, se restringió el ámbito de los derechos objeto de regulación mediante Ley Orgánica y, por otra, se introdujo la cláusula que prevé que a lo largo del texto constitucional se incluyan diferentes materias cuyo desarrollo legal quedaría reservado también a dicho tipo normativo (43).

(40) La Ley se dictó tras unos cambios ministeriales que pretendían asentar las reformas iniciadas en 1957 con el fin de modernizar el sistema, recogiendo «una línea político ideológica que pretendía mantener intacto el depósito de la tradición y de los valores dominantes, al tiempo que modernizaba las estructuras económicas y administrativas sin poner en peligro el la estabilidad global del sistema». El proyecto de Ley Orgánica del Estado fue sometido a referéndum el 14 de diciembre de 1966: SOLÉ-TURA, J., Introducción al Régimen Político Español, Barcelona, 1972, pp. 40-44. No es necesario señalar que se trataba de un proceso plebiscitario, pues faltaban los elementos mínimos democráticos de libertad y transparencia.

(41) El artículo 46 de la Constitución francesa de 1958 dispone: "Las Leyes a las cuales la Constitución confiera el carácter de Leyes Orgánicas serán votadas y modificadas en las siguientes condiciones. El proyecto o la proposición no será sometido al debate y a la votación de la primera asamblea que lo haya recibido, sino después de quince días de su presentación. Se aplicará el procedimiento del artículo 45. No obstante, si no hubiere acuerdo entre las dos asambleas, el texto no podrá ser aprobado por la Asamblea Nacional en última lectura sino por mayoría absoluta de sus miembros. Las Leyes Orgánicas relativas al Senado deberán ser votadas en los mismos términos por las dos asambleas. Las Leyes Orgánicas no podrán ser promulgadas sino después de declarada por el Consejo Constitucional su conformidad con la Constitución». Vid. ÁLVAREZ VÉLEZ, M. I., "La Constitución de Francia», Revista de las Cortes Generales, núm. 75, 2008, pp. 387- 446.

(42) BOC, de 5 de enero de 1978.

(43) La redacción del Informe de la Ponencia fue el siguiente: «Son Leyes Orgánicas las relativas al desarrollo de las libertades públicas, a la organización de las instituciones centrales del Estado, las que aprueben los Estatutos de Autonomía y el régimen electoral y las demás previstas en la Constitución»: BOC de 17 de abril de 1978. 
No obstante la redacción definitiva, al fin artículo 81, se debió a la labor de la Comisión Mixta Congreso-Senado (44).

La novedad sorprendió a algún sector de la doctrina y de los propios parlamentarios, quizá por los antecedentes señalados, a los que se añadían las dudas acerca de la posición de dichas Leyes en el sistema de fuentes. De modo que, aunque la inclusión de las Leyes Orgánicas en la Constitución no resultó un asunto polémico, ni dio lugar a importantes debates en las Cámaras, algunas enmiendas pusieron de manifiesto cierto desconcierto entre los parlamentarios acerca de su alcance y significado (45).

En realidad se trataba de establecer una reserva para la regulación legal de determinadas materias diferenciadas de las demás Leyes por razón del procedimiento de "aprobación, modificación o derogación» que exige mayoría absoluta del Congreso de los Diputados en una votación final sobre el conjunto del proyecto, conforme a las disposiciones del artículo 81, precepto que crea la Ley Orgánica, dispone las materias que deberán regularse por dicha norma y exige la mayoría señalada para su aprobación, lo que se ha entendido también como el deseo constituyente de alargar en el tiempo el consenso constitucional para las materias elegidas (46).

Acerca de las materias es lugar común entender que las reservadas a la Ley Orgánica por la Constitución, bien en el artículo 81.1 o en otros preceptos constitucionales que se desgranan a lo largo de todo el texto, no responden a un criterio preestablecido, sino que se trata de una serie de materias heterogéneas (47). Sin embargo, sí puede afirmarse que todas

(44) BOC, de 28 de octubre de 1978.

(45) Entre las enmiendas presentadas sobre la Ley Orgánica suele destacarse la del Senador Ollero Gómez, de la Agrupación Independiente, que consideró la prevista Ley Orgánica «una puerta abierta para convertir el poder legislativo en una especie de poder constituyente permanenten; $y$, para evitar esta situación, el Senador proponía establecer «para ciertas Leyes Orgánicas una especie de reserva de Ley Constitucional». Recelos innecesarios, puesto que la Ley Orgánica difícilmente podría desarrollar efectos sobre la Constitución, cuya modificación queda suficientemente garantizada y reforzada en elTítulo $X$ del propio texto Constitucional, totalmente separada del desarrollo constitucional ya sea mediante Ley Orgánica, ordinaria, o autonómica. Estas y otras enmiendas sobre la Ley Orgánica presentadas por el Senador Ollero pueden verse en: OLLERO, C., Derecho y Teoría Política en el proceso constituyente español, Madrid, 1986, pp. 83-87.

(46) Algún sector de la doctrina entendió que la mayoría exigida en el artículo 81.2 de la Constitución para la aprobación de la Ley Orgánica se traducía en una supremacía formal de la norma. Una polémica resuelta por la propia doctrina, debido sobre todo a la definición de la posición de cada instrumento normativo, y también a la jurisprudencia constitucional. La posición que ocupa la Ley Orgánica en el sistema de fuentes no puede resolverse por el principio de jerarquía. El criterio que define la reserva de Ley Orgánica es el principio de competencia. Son Leyes Orgánicas las expresamente reservadas por la Constitución a este tipo de Leyes, reserva que se establece en el artículo 81.1 de la Constitución.

(47) «En fin, el elenco de estas Leyes (Orgánicas) es tan heterogéneo que no resulta posible encontrar en él un hilo conductor. Seguramente no hay otra explicación a las reservas constitucionales de Ley Orgánica que la conveniencia política que en ello creyó encontrar el constituyente. Éste quiso 
son materias esenciales para el establecimiento de un Estado democrático de Derecho que garantice una tabla rica de derechos y libertades fundamentales y asegure una organización constitucional fundada en la participación y el pluralismo. Entre ellas parece destacar la reserva de Ley Orgánica para los derechos y libertades de los ciudadanos, materia que estuvo presente desde el inicio del proceso constituyente, aunque, según vimos, con algunos vaivenes.

En todo caso, desde el Anteproyecto está clara la voluntad constituyente de que los derechos de los ciudadanos, especialmente aquellos que aseguraban la implantación real de un sistema "nuevo" de democracia y libertad fueran desarrollados mediante Ley Orgánica (48). Y, de hecho, en la redacción final del artículo 81.1 la primera materia que se proclama como objeto de Ley Orgánica son "las relativas al desarrollo de los derechos fundamentales y de libertades públicas".

Las dudas surgieron a la hora de determinar la extensión de esta materia. Es sabido que la primera tentación de la doctrina fue identificar los preceptos contenidos en los artículos recurribles en amparo constitucional, señalados en el artículo 53.2, con los que se reservan a la Ley Orgánica. Una interpretación que el Tribunal Constitucional declaró contraria a los preceptos constitucionales, según se advierte a continuación.

Los derechos susceptibles de recurso de amparo en sede constitucional, son los contenidos en el artículo 14, en la Sección primera del Capítulo segundo, y en artículo 30.2 de la Constitución. En cuanto a la Sección primera del Capítulo segundo resulta evidente el desarrollo mediante Ley Orgánica, puesto que se trata de «derechos fundamentales y libertades públicas" epígrafe que coincide con la expresión utilizada en el artículo 81. Por tanto, el problema se centraba, en los artículos 14 y 30.2.

En lo que se refiere al artículo 14, las dudas acerca de la naturaleza de su regulación fueron resueltas por el propioTribunal Constitucional: «Esta equiparación entre materias que pueden ser objeto de recurso de amparo y las que han de ser reguladas por Ley Orgánica no resulta constitucionalmente defendible. En primer lugar, el artículo 53 de la Constitución establece que cualquier ciudadano podrá recabar, a través del recurso de amparo, la tutela de las libertades y los derechos reconocidos en el artículo 14 y en la Sección primera del Capítulo segundo, mientras que el artículo 81.1, al definir las materias propias de la Ley Orgánica, se refiere

que alunas instituciones o decisiones estuvieran arropadas por una más acentuada garantía de las minorías, para prolongar así el clima de consenso que había posibilitado la transición política»: TORRES DEL MORAL, A., Principios de Derecho Constitucional Español, Madrid, 2004, p. 201.

(48) Recordemos que la redacción del artículo 81, entonces artículo de la Comisión Constitucional suprimió la regulación de los derechos delTítulo I de la Constitución, según rezaba el Anteproyecto, pero incluyó «las relativas al desarrollo de las libertades públicas». 
al «desarrollo de los derechos fundamentales y de las libertades públicas» que es precisamente la rúbrica utilizada para designar el conjunto de los artículos comprendidos en la Sección primera de Capítulo segundo.

En lo referente reserva de Ley Orgánica para el desarrollo del artículo 30.2, la solución derivó también de la doctrina del Tribunal Constitucional que tuvo ocasión de manifestarse sobre esta cuestión a raíz del recurso de inconstitucionalidad presentado por el Defensor del Pueblo contra la Ley 48/1984, de 26 de diciembre, reguladora de la objeción de conciencia y de la prestación social sustitutoria. Esta fue la respuesta del alto Tribunal: «El derecho a la objeción de conciencia, aún en la hipótesis de estimarlo fundamental no está sujeto a la reserva de Ley Orgánica por no estar incluido en los artículos 15 al 29 de la Constitución relativos a la enumeración de los derechos y libertades fundamentales" (49).

De modo que no sólo se resolvía el recurso que dio lugar a la Sentencia, sino que el alto Tribunal reiteraba el ámbito de la regulación mediante Ley Orgánica a los «derechos fundamentales y las libertades públicas» (50).

Aclaradas estas cuestiones conviene hacer una aproximación a criterios jurídicos que orienten el alcance de la expresión "desarrollo" que la Constitución utiliza para definir la regulación de "los derechos fundamentales y las libertades públicas». Adelantamos que este punto es complejo, pues no sólo la postura del Tribunal Constitucional no es clara en todos los puntos, sino que ni la doctrina ni el legislador parecen haber optado por una línea definida. Así, el Tribunal Constitucional ha llegado a declarar que la Ley Orgánica constituye un instrumento jurídico «únicamente para supuestos tasados y excepcionales» (51).

En cuanto a la doctrina, afirman GARCÍA DE ENTERRÍA y FERNÁNDEZ, que el desarrollo por Ley Orgánica «debe ser el mínimo indispensable para que la norma básica contenida en la propia Constitución pueda funcionar correctamente y alcanzar así la operatividad social a la que constitucionalmente esta avocada» (52).

Por otra parte, y, en lo que se refiere específicamente al "desarrollo» de los derechos fundamentales y libertades públicas, las posiciones doctrinales pueden ser de diferente signo, puesto que en el contenido de la Constitución no hay indicios que orienten en una determinada dirección.

(49) STC 6/1987, de 28 de enero.

(50) Doctrina cualificada optó, desde la aprobación de la Constitución, por una interpretación de la regulación por Ley Orgánica restringida a los derechos y libertades contenidos en la Sección primera del Capitulo segundo delTítulo I de la Constitución. Por todos: SANTAMARÍA PASTOR, J. A., "Las Leyes Orgánicas", Revista de Derecho Político UNED, núm. 4, 1979, pp. 46-48.

(51) STC 5/1981, de 13 de febrero.

(52) GARcíA DE ENTERRÍA, E. y FERNÁNDEZ, T. R., Curso de Derecho Administrativo, Navarra, 2008, p. 140. 
Por ello SANTAMARÍA señaló que podrían darse una pluralidad de respuestas «desde la maximalista, según la cual sería desarrollo cualquier regulación que de cualquier forma, incluso tangencial, parcial o indirecta, que afectase al régimen de estos derechos y libertades, hasta la minimalista, que exigiría reservar el concepto para las Leyes que de modo directo, frontal y global, aborden la regulación de un derecho» (53). El propio autor considera en su discurso que la segunda opción, la minimalista, es la preferible y es, además, la opción exigida por el Tribunal Constitucional (54).

Una expansión excesiva del término "desarrollo» para la regulación de los derechos fundamentales y las libertades públicas daría lugar a una proliferación de las Leyes Orgánicas, lo que no sólo sería contrario al espíritu constituyente, sino que podría dificultar la labor legislativa, especialmente en unas Cámaras sin una mayoría suficiente para aprobación de estas Leyes. La Ley Orgánica es, como ya avanzamos, un instrumento jurídico creado para alargar el consenso parlamentario en materias relevantes, y entre ellas destacan los derechos fundamentales y las libertades públicas, pero no sólo no es necesario exigir que toda la materia directa o indirectamente relacionada con estos derechos sea materia de Ley Orgánica, sino que esta posición parlamentaria hubiera sido insostenible en las Cámaras.

Sin embargo, sí hay un límite mínimo; esto es, el núcleo esencial del derecho fundamental o libertad pública objeto de regulación debe serlo por Ley Orgánica. Entendemos, así, que ese núcleo esencial al que se refiere la Sentencia del Tribunal Constitucional 6/1981, de 16 de marzo, debería al menos abarcar el "contenido esencial» del derecho, según dispone el artículo 53.1 de la Constitución.

En cuanto al significado constitucional del respeto al contenido esencial, el Tribunal Constitucional señaló dos criterios a tener en cuenta. En primer lugar «el contenido esencial de un derecho es aquella parte de su contenido sin el cual el citado derecho pierde su peculiaridad, es decir aquello que lo hace recognoscible como derecho perteneciente a un determinado tipo, de forma que «los especialistas en Derecho puedan responder si lo que el legislador ha regulado se ajusta o no a lo que generalmente se entiende por derecho de un determinado tipo". Por otra parte, el Tribunal declara también que el contenido esencial es aquel ineludiblemente necesario para que el derecho permita a su titular la satisfacción de sus intereses jurídicamente protegidos; así, se lesionará «el contenido esencial cuando el derecho quede sometido a limitaciones que lo hagan

(53) SANTAMARÍA PASTOR, J. A., Principios de Derecho Administrativo, Volumen I, Madrid, 2000, p. 223.

(54) SSTC 6/1982; 98/1985; y, 161/87, entre otras. 
impracticable, lo dificulten más allá de lo razonable o lo despojen de la recesaría protección». El Tribunal considera que los dos criterios no son alternativos, sino complementarios (55).

En consecuencia, el contenido esencial de un derecho fundamental o una libertad pública, recogido en la Sección primera del Capítulo segundo del Título I debe ser, por imperativo constitucional, regulado por Ley Orgánica, lo que no significa que este sea en exclusiva su ámbito, pues la Ley Orgánica puede abarcar toda la regulación del derecho o libertad correspondiente, o bien el legislador podrá optar por dejar ciertas materias, - que en ningún caso afecten al contenido esencial del derecho-, a la Ley ordinaria.

Despejados parte de los conflictos iniciales que presentaba la constitucionalización, en 1978, de las Leyes Orgánicas, su naturaleza y su ámbito, la doctrina ha ido abriendo nuevas puertas al estudio de estas normas, estudios que no se limitan al plano teórico. La Ley Orgánica dispone de un relevante estatuto en el sistema normativo español, y sus efectos afectan no sólo al sistema de fuentes, sino al propio orden constitucional. En esta línea, BARCELÓ i SERRAMALERA aborda la naturaleza de la Ley Orgánica planteando una cuestión previa de hondo calado constitucional; se trata de delimitar si hay que conceptualizar las Leyes Orgánicas "como pieza del sistema de fuentes o bien como norma de carácter competencial». Y así continúa esta autora: «en el primer caso, los elementos estructurales a regular mediante Ley Orgánica vendrían prefijados por el propio alcance de los títulos competenciales atribuidos al Estado por el artículo 149.1 de la Constitución acerca de un determinado derecho o libertad y, en el segundo, a este contenido se le añadiría una facultad autónoma para regular otros aspectos allí no contemplados que provendría de un entendimiento competencial del artículo 81.1 de la Constitución" (56).

El asunto así planteado mueve posturas doctrinales cuyas raíces proceden de las primera doctrinas post-constitucionales y que se pueden encontrar en la obra que hemos tomado, en este punto, de referencia (57). Siguiendo con nuestros intereses, recordamos que la distribución de competencias entre el Estado y las Comunidades Autónomas no está sólo definido en el artículo 149. La Constitución establece un modelo abierto, que deja al legislador importantes márgenes de decisión. El desarrollo constitucional sobre el orden competencial del nuevo Estado descentralizado que la Constitución crea se basa en diferentes instrumentos jurídi-

(55) STC 11/1981, de 8 de abril.

(56) BARCELÓ i SERRAMALERA, M., La Ley Orgánica. Ámbito material y posición en el sistema de fuentes, Barcelona, 2004, pp. 50, 51.

(57) Ibidem, pp. 50 y ss. 
cos. Incluso la legislación autonómica incide en la distribución, ya sea por acción o por omisión.

En esta estructura competencial dinámica -como lo es siempre el ordenamiento-, la Ley Orgánica tiene un papel relevante diseñado por el propio constituyente. No creemos que la supuesta oposición entre Ley Orgánica como «pieza del sistema de fuentes o como norma de carácter competencial» pueda desembocar en la consideración de diferentes enfoques sobre la naturaleza y efectos de este tipo de Ley. La naturaleza de la Ley Orgánica es la que establece la Constitución. No obstante si afirmar que los "derechos fundamentales y las libertades públicas», al menos en lo que se refiere al contenido esencial, deben ser regulados mediante Ley Orgánica por las Cortes Generales Ileva consigo entender que es un instrumento jurídico que forma parte de los elementos que tienen la misión de establecer la distribución competencial, así será, pero, en todo caso, continúa siendo una pieza del sistema de fuentes.

En realidad, el constituyente se preocupó especialmente en asegurar la eficacia de los derechos fundamentales y las libertades públicas para todos los ciudadanos sin distinción. Y la Ley Orgánica es, sin duda, un elemento esencial para la obtención de dichos fines. En este sentido la voluntad constituyente se manifiesta claramente en el artículo 81, pero también en el 139 (58) y en el 149. Todos ellos preceptos que persiguen en aras del principio de igualdad, el disfrute para todos los españoles de los mismos derechos fundamentales y libertades públicas. Por ello, carece de sentido afirmar que la reserva de Ley Orgánica debe someterse a la distribución competencial que lleva a cabo el artículo 149 de la Constitución. Este precepto inicia el listado de competencias del Estado declarando que le corresponde "la regulación de las condiciones básicas que garanticen la igualdad de todos los españoles en el ejercicio de los derechos y en el cumplimiento de los deberes constitucionales".

Una disposición de carácter general y claras finalidades que, en lo que se refiere a los derechos fundamentales y libertades públicas, se complementa con el contenido del artículo 81, que exige regulación mediante Ley estatal y mayoría absoluta del Congreso para la aprobación de las Leyes que los regulen. En último término, garantías normativas para la protección de los derechos fundamentales y las libertades públicas, a las que se unen las prohibiciones de regulación por el ejecutivo que establecen los artículos 82 y 86 de la Constitución en relación al Decreto Legislativo y el Decreto-Ley. Normativa constitucional que manifiesta que la protección de los derechos de los ciudadanos y la garantía del principio de igualdad fueron consideradas desde el primer momento constituyente como ele-

(58) El apartado 1 del artículo 139 de la Constitución dispone: «Todos los españoles tienen los mismos derechos y obligaciones en cualquier parte del territorio del Estado". 
mentos esenciales del Estado que se constituía. Así lo advertía ENTRENA CUESTA: "La igualdad de los ciudadanos ante la Ley constituye uno de los principios que más cuidadosa y reiteradamente consagra la Constitución» (...) "por otra parte, el Estado tiene competencia exclusiva sobre la regulación de las condiciones básicas que garanticen la igualdad de todos los españoles en el ejercicio de los derechos y en el cumplimiento de los deberes constitucionales (artículo $149,1.1 .^{\circ}$ )" (59). El mismo autor señala la importancia del contenido del artículo 139 de la Constitución y cita la Sentencia del Tribunal Constitucional de 13 de febrero de 1981 que incide en la igualdad de todos los españoles para el disfrute de los derechos y libertades en cualquier parte del territorio del Estado.

\section{La constitucionalidad de las declaraciones de derechos en los nuevos Estatutos de Autonomía}

Las reformas estatutarias centraron la polémica a lo largo de la VIII Legislatura, que comenzó en 2004 y terminó en 2008 (60). Durante esta Legislatura se han modificado seis Estatutos de Autonomía:

- Ley Orgánica 1/2006, de 10 de abril, de Reforma de Ley Orgánica 5/1982, de 1 de julio, de Estatuto de Autonomía de la Comunidad Valenciana.

- Ley Orgánica 6/2006, de 19 de julio, de reforma del Estatuto de Autonomía de Cataluña.

- Ley Orgánica 1/2007, de 28 de febrero, de reforma del Estatuto de las Illes Balears.

- Ley Orgánica 2/2007, de 19 de marzo, de reforma del Estatuto de Autonomía para Andalucía.

- Ley Orgánica 5/2007, de 20 de abril, de reforma del Estatuto de Autonomía de Aragón.

- Ley Orgánica 14/2007, de 30 de noviembre, de reforma del Estatuto de Autonomía de Castilla y León.

En la presente Legislatura (2008-2012) están en tramitación las reformas de los Estatutos de Extremadura y de Castilla La Mancha.

(59) ENTRENA CUESTA, R., "Artículo 139», en GARRIDO FALLA, F., Comentarios a la Constitución, Madrid, 1985, pp. 215 y 217.

(60) En este punto son importantes los siguientes trabajos publicados recientemente: ÁLVAREZ CONDE, E., Reforma constitucional y reformas estatutarias, Madrid, 2007. ORTEGA ÁLVAREZ, L. (dir.), La reforma del Estado autonómico, Madrid, 2005. SANZ PÉREZ, A. L., La reforma de los Estatutos de Autonomía (con especial referencia a los Estatutos de Autonomía de Cataluña y de la Comunidad Valenciana, Navarra, 2006. 
Algún autor ha señalado que esta etapa no ha supuesto una simple reforma de los Estatutos, sino una auténtica refundación de las Comunidades Autónomas. Así, señala CONTRERAS CASADO que la reforma del Estatuto Vasco, conocida como Plan Ibarreche, que se presentó al finalizar la VII Legislatura (2000-2004), fue el principio de esa modificación del Estado de las Autonomías, pues «no se trataba en rigor de una reforma, sino de un replanteamiento de las relaciones de esa Comunidad con el Estado que desbordaba ampliamente el marco constitucional" y añade el mismo autor que lo grave del caso catalán no es tanto la modificación total del Estatuto por otro, sino «el espíritu de ruptura y de refundación que impregna todo el texto estatutario" (61).

Efectivamente. Especialmente polémica ha sido la reforma del Estatuto de Cataluña, contra la que se han presentado varios recursos de inconstitucionalidad (62). Los dos recursos principales son los presentados por el Partido Popular y por el Defensor del Pueblo y en ambos se señala que las normas estatutarias sobre derechos son inconstitucionales, porque no son materia de los Estatutos de Autonomía (63).

En general los Estatutos incluyen un primer o segundo Título en el que se relacionan los derechos. Siguiendo el orden cronológico de aprobación los contenidos son los siguientes:

El Estatuto de Autonomía de la Comunidad Valenciana dedica elTítulo II a los «Derechos de los Valencianos y Valencianas». En este título se reconoce en primer lugar que "los valencianos y valencianas, en su condición de ciudadanos españoles y europeos, son titulares de los derechos, deberes y libertades reconocidos en la Constitución Española y en el ordenamiento de la Unión Europea y en los instrumentos internacionales de pro-

(61) Vid. CONTRERAS CASADO, M., "Las reformas de los Estatutos de Autonomía. Viejos y nuevos tiempos en la construcción del Estado autonómico", en Anuario jurídico de la Rioja, núm. 11, 2006, p. 21. Sobre la intervención del Tribunal Constitucional, en relación con la «Propuesta de Estatuto Político de Euskadi» conocido como «Plan Ibarrexte», vid. FERNÁNDEZ FARRERES, G., «EI Tribunal Constitucional ante las reformas estatutarias», Revista Asamblea, núm. 21, 2009, pp. 145-168 y especialmente las pp. 148-152.

(62) Se han presentado siete recursos de inconstitucionalidad contra el Estatuto Catalán: cinco Comunidades Autónomas han presentado recurso (Aragón, Illes Balears, Comunidad de Valencia, Región de Murcia y La Rioja), un recurso del partido popular en el Congreso de los Diputados y el último recurso presentado por el Defensor del Pueblo. Aragón, Illes Balears y Valencia basan su recurso en relación al Archivo de la Corona de Aragón. Los recursos de las Comunidades de Región de Murcia y La Rioja se refieren a impugnación de las competencias en materia de aguas. Vid., sobre el tema, FERNÁNDEZ FARRERES, G., op. cit., especialmente las pp. 159-165.

(63) El Defensor del Pueblo presenta el Recurso núm. 1/2006, interpuesto el 19 de septiembre, en relación con diversos preceptos la Ley Orgánica 6/2006, de 19 de julio, de reforma del Estatuto de Autonomía de Cataluña. Por su parte el Partido Popular presenta el Recurso núm. 8675/2006, en relación con diversos preceptos de la Ley Orgánica 6/2006, de 19 de julio, de reforma del Estatuto de Autonomía de Cataluña. Este último es el más extenso pues se impugnan varios párrafos del Preámbulo, 124 artículos (de los 223 que tiene el Estatuto), 9 disposiciones adicionales (de un total de 15$)$ y las disposiciones finales $1 .^{a}, 2 .^{a}$ y $3 .^{a}$. 
tección de los derechos humanos, individuales y colectivos, en particular, en la Declaración Universal de Derechos Humanos; en los Pactos Internacionales de Derechos Civiles y Políticos y de Derechos Económicos, Sociales y Culturales; en la Convención Europea de Derechos del Hombre y Libertades Fundamentales, y en la Carta Social Europea» (artículo 8).

Se recogen también otros derechos: derecho a una buena administración y el acceso a los documentos de las instituciones y administraciones públicas valencianas (artículo 9); los derechos sociales de los valencianos, que se reconocerán a través de la elaboración por Ley de la Carta de Derechos Sociales de la Comunitat Valenciana (artículo 10); derecho a la participación plena en la vida laboral, social, familiar y política sin discriminaciones de ningún tipo (artículo 11); la protección y defensa de la creatividad artística, científica y técnica (artículo 12); los derechos de las personas afectadas de discapacidad (artículo 13); derechos y necesidades de las personas que hayan sufrido daños causados por catástrofes naturales y sobrevenidas (artículo 14); derecho de los ciudadanos valencianos en estado de necesidad a la solidaridad y a una renta de ciudadanía (artículo 15); derecho de acceso a una vivienda digna de los ciudadanos valencianos (artículo 16); el derecho de los valencianos y valencianas a disponer del abastecimiento suficiente de agua de calidad (artículo 17); derechos del sector agrario valenciano (artículo 18); derecho a la seguridad y la salud en el trabajo (artículo 19).

El Estatuto de Autonomía de Cataluña dedica todo elTítulo I a los «Derechos, deberes y principios rectores" y a lo largo de cinco capítulos enumera los derechos, siguiendo el esquema de la Constitución española (64).

El Capítulo I denominado "Derechos y deberes del ámbito civil y social" recoge los siguientes derechos: derechos de las personas (artículo 15); derechos en el ámbito de las familias (artículo 16); derechos de los menores (artículo 17); derechos de las personas mayores (artículo 18); derechos de las mujeres (artículo 19); derecho a vivir con dignidad el proceso de la muerte (artículo 20); derechos y deberes en el ámbito de la educación (artículo 21); derechos y deberes en el ámbito cultural (artículo 22); derechos en el ámbito de la salud (artículo 23); derechos en el ámbito de los servicios sociales (artículo 24); derechos en el ámbito laboral (artículo 25); derechos en el ámbito de la vivienda (artículo 26); derechos y deberes con relación al medio ambiente (artículo 27); y derechos de los consumidores y usuarios (artículo 28).

En el Capítulo II denominado "De los derechos en el ámbito político y de la Administración» se recogen tres derechos: derecho de participación

(64) Sobre la similitud en la estructura adoptada por el Título I del Estatuto de Cataluña señala SANZ PÉREZ que la distinción de los derechos "es más conceptual que real, pues no hay diferencia entre unos y otros a efectos de protección, simplemente porque el Estatuto de Autonomía no puede disponer semejantes efectos». Vid. SANZ PÉREZ, A. L., op. cit., p. 80. 
(artículo 29); derechos de acceso a los servicios públicos y a una buena Administración (artículo 30); y el derecho a la protección de los datos personales (artículo 31). En el Capítulo III, denominado Derechos y deberes lingüísticos (arts. 32 a 36), se reconoce el derecho de todas las personas "a no ser discriminadas por razones lingüísticas», regulándose que los "ciudadanos tienen el derecho de opción lingüística» ante las Administraciones públicas y las instituciones estatales. Finalmente, se hace referencia a los derechos lingüísticos de los consumidores y usuarios (artículo 34), a los derechos lingüísticos en el ámbito de la enseñanza (artículo 35) y a los derechos con relación al aranés (artículo 36).

Las "Garantías de los derechos estatutarios» quedan recogidas en el Capítulo IV (arts. 37 y 38) de este Título I que estamos analizando. Se encomienda la tutela de los derechos al Consejo de Garantías Estatutarias regulado en el artículo 76 del Estatuto y que en cierta medida emula como institución al Tribunal Constitucional (65). El Título finaliza con el Capítulo $V$ dedicado a los "Principios rectores» en el que se señala que "los poderes públicos de Cataluña deben orientar las políticas públicas de acuerdo con los principios rectores que establecen la Constitución y el presente Estatuto" (artículo 39). Se establece así el compromiso de los poderes públicos en la protección de las personas y de las familias (artículo 40), con el cumplimiento del principio de igualdad de oportunidades entre mujeres y hombres (artículo 41), con la realización de políticas públicas que fomenten la cohesión social y que garanticen un sistema de servicios sociales (artículo 42), con la promoción de la participación social, individual y asociativa en la elaboración, prestación y evaluación de las políticas públicas (artículo 43), o en relación a la protección de consumidores y usuarios (artículo 49).

En el Estatuto de las Illes Balears es el Título II (arts. 13 a 29) denominado "De los derechos, los deberes y las libertades de los ciudadanos de las Illes Balears» el que recoge la enumeración de los derechos. El artículo 13 reconoce que los «ciudadanos de las Illes Balears, como ciudadanos españoles y europeos, son titulares de los derechos, deberes y libertades reconocidos en la Constitución, en el ordenamiento de la Unión Europea y en los instrumentos internacionales de protección de los derechos humanos, individuales y colectivos: en particular, en la Declaración de Derechos Humanos, en los Pactos Internacionales de Derechos Civiles y Políticos y de Derechos Económicos, Sociales y Culturales; en la

(65) Esta Institución está regulada por la Ley 2/2009, de 12 de febrero, del Consejo de Garantías Estatutarias y establece en su artículo 3.1 que «está integrado por nueve miembros, que deben ser juristas de competencia y prestigio reconocidos, con más de quince años de experiencia profesional, y deben tener la condición política de catalanes». Vid., al respecto, ALBERTí ROVIRA, E., "EI nuevo Consejo de Garantías Estatutarias del Estatuto de Autonomía de Cataluña como instrumento de garantía de los derechos", Revista Vasca de Administración Pública, núm. 82, 2008, pp. 15-26. 
Convención Europea de Derechos del Hombre y Libertades Fundamentales y en la Carta Social Europea». A continuación se recogen los siguientes derechos: derechos en relación con las Administraciones públicas (artículo 14); derechos sociales (artículo 16); no discriminación por razón de sexo (artículo 17); el derecho de los ciudadanos de las Illes Balears en estado de necesidad a la solidaridad y a una renta mínima de inserción (artículo 21); derecho a la salud (artículo 25); y derecho a una educación de calidad (artículo 26).

El Estatuto de Autonomía para Andalucía, sigue el esquema del Estatuto Catalán y es el Título I, «Derechos sociales, deberes y políticas públicas» el que recoge a lo largo de cuatro capítulos la parte dogmática del Estatuto. En el Capítulo I se marca la titularidad y alcance de los derechos (arts. 12 y 13) así como el principio de no discriminación (artículo 14). En el Capítulo II «Derechos y deberes» (arts. 15 al 37), se recogen los siguientes: igualdad de género (artículo 15); protección contra la violencia de género (artículo 16); protección de la familia (artículo 17); derechos de los menores (artículo 18); derechos de los mayores (artículo 19); derecho a declarar la voluntad vital anticipada (artículo 20); derechos a la educación (artículo 21); derecho a la protección de la salud (artículo 22); derechos de los personas con discapacidad o dependencia (artículo 24; protección del medio ambiente (artículo 28); y derecho a participar en condiciones de igualdad en los asuntos públicos de Andalucía (artículo 30). En el Capítulo III (artículo 37) se enumeran los «Principios rectores de las políticas públicas" y en el Capítulo IV (arts. 38 a 41) se abordan las Garantías de los derechos con referencias el texto constitucional realizando especial mención a la figura del «Defensor o Defensora del Pueblo Andaluz» (artículo 41).

El Estatuto de Autonomía de Aragón también dedica todo el Título I a los Derechos y principios rectores", dividiéndolo en dos capítulos. En el Capítulo I "Derechos y deberes de los aragoneses y aragonesas" se establece que «quienes gocen de la condición política de aragonés son titulares de los derechos regulados en este capítulo, sin perjuicio de su extensión a otras personas, en los términos que establezcan este Estatuto y las Leyes" (artículo 11.2). Se recogen los derechos de las personas (artículo 12); derechos y deberes en relación con la cultura (artículo 13); derecho a la salud (artículo 14); derecho de participación (artículo 15); derechos en relación con los servicios públicos (artículo 16); derechos de consumidores y usuarios (artículo 17); derechos y deberes en relación con el medio ambiente (artículo 18); derechos en relación con el agua (artículo 19). En el Capítulo II (arts. 20 a 31) «Principios rectores de las políticas públicas" se recoge el compromiso de los poderes públicos de Aragón en relación a los derechos de educación (artículo 21); a la conservación, conocimiento y difusión del patrimonio cultural, histórico y artístico de Aragón (artículo 22); a garantizar un sistema público de servicios 
sociales (artículo 23); a la protección personal y familiar (artículo 24); al empleo y al trabajo (artículo 26); a la vivienda (artículo 27); y al fomento de la integración social de las personas inmigrantes (artículo 29).

El Estatuto de Autonomía de Castilla y León recoge en el Título I los "Derechos y principios rectores» a lo largo de cinco capítulos. En el Capítulo I "Disposiciones generales» se señala que "tienen la condición política de ciudadanos de Castilla y León todos los españoles que, de acuerdo con las Leyes del Estado, tengan vecindad administrativa en cualquiera de los municipios integrados en el territorio de la Comunidad" (artículo 7) y se establece también los derechos de los que gozan los Castellanos y leoneses en el exterior (artículo 9) y derechos de los extranjeros con vecindad administrativa en la Comunidad (artículo 10).

En el Capítulo II "Derechos de los castellanos y leoneses" nos encontramos con la tabla de derechos, entre otros, los derechos de participación en los asuntos públicos (artículo 11); el derecho a una buena Administración (artículo 12); y los derechos sociales enumerados en el artículo13 a la educación, a la salud, al acceso a los servicios sociales, derechos de las personas mayores, derechos de los menores de edad, derechos de las personas en situación de dependencia y de sus familias, derechos de las personas con discapacidad.

El Capítulo III (artículo 15) recibe la denominación de «Deberes de los castellanos y leoneses» haciéndose referencia al deber de contribuir al sostenimiento del gasto público de acuerdo con su capacidad económica, de conservar y proteger el medio ambiente y hacer un uso responsable de los recursos naturales, de colaborar en las situaciones de catástrofes y emergencia.

El Capítulo IV comprende los «Principios rectores de las políticas públicas de Castilla y León» (artículo 16) destacándose como objetivos de esas políticas la prestación de unos servicios públicos de calidad, el crecimiento económico sostenible, la creación de empleo estable y de calidad, la garantía de la seguridad y salud laboral de los trabajadores, el fomento del diálogo social como factor de cohesión social y progreso económico, el apoyo a los sectores agrícola, ganadero y agroalimentario, la plena integración de los jóvenes en la vida pública y en la sociedad, la protección integral de las distintas modalidades de familia, la no discriminación y el respeto a la diversidad de los distintos colectivos étnicos, culturales y religiosos...

Termina el Título con el Capítulo V (artículos 17 y 18) «Garantías de los derechos y principios estatutarios» en el que se regula la institución del Procurador del Común como «el Alto Comisionado de las Cortes de Castilla y León, designado por éstas, que actúa con independencia para la protección y defensa de los derechos constitucionales de los ciudadanos y de los derechos y principios reconocidos en el presente Estatuto frente a 
la Administración de la Comunidad, la de sus entes locales y la de los diferentes organismos que de éstas dependan».

En cualquier caso las críticas al modelo que adoptan los nuevos Estatutos de Autonomía han girado en torno a dos cuestiones. En primer lugar, en aspectos de oportunidad política. En segundo lugar, acerca de la duda jurídica de esta inclusión.

La primera cuestión excede al trabajo que hemos elaborado. Es cierto que sobre este punto el planteamiento es permitir que todos los Estatutos incluyan esa declaración de derechos y diluir así la problemática en torno al Estatuto Catalán.

La segunda cuestión nos parece más relevante para nuestro estudio, porque se trataría de una objeción sobre la constitucionalidad de los Estatutos. Aquí el asunto es complejo, pues se trata de Leyes Orgánicas que como tales han sido aprobadas por las Cortes Generales y no son reformas que se hayan aprobado por los órganos autonómicos. Así, junto a normas vigentes para toda España, hay otras cuya vigencia está limitada al territorio de la correspondiente Comunidad Autónoma a pesar de haber sido aprobadas por las Cortes. De esos textos aparece una «diferenciación en el régimen jurídico y, por tanto, una cierta diversidad de derechos y obligaciones de los españoles en las distintas partes del territorio nacional» (66).

Estas incorporaciones en el ámbito de los derechos ya han dado lugar a pronunciamientos diversos tanto por parte del Tribunal Constitucional, como también por parte de la doctrina.

En primer lugar, el Tribunal Constitucional ha tenido oportunidad de pronunciarse en la Sentencia 247/2007, de 12 de diciembre (67). Señala el Tribunal que «nada determina que el régimen jurídico de los derechos constitucionales quede sustraído a las reglas del reparto competencial, pues ya sabemos que ni el artículo 53 ni el 81, ambos de la Constitución, son preceptos que distribuyan competencias, por lo que, salvadas las garantías de unidad aludidas (artículo 81.1 de la Constitución), es posible, (...) que la normativa autonómica, dictada dentro de los ámbitos competenciales que le sean propios, incida en la regulación del régimen jurídico de esos derechos, respetando siempre, naturalmente, las determinaciones que pudieran seguirse de las competencias estatales». En este punto creemos que el Tribunal descarta claramente que el artículo 81 de la Constitución afecte al reparto competencial, opinión que creemos está claramente equivocada en la línea que han mantenido otros autores.

(66) Informe del Consejo de Estado sobre modificaciones de la Constitución Española, 2006, p. 194.

(67) Se trata del Recurso de Inconstitucionalidad interpuesto por el Gobierno de la Comunidad Autónoma de Aragón contra el artículo 20 de la Ley Orgánica 1/2006, de 10 de abril, de reforma de la Ley Orgánica 5/1982, de 1 de julio, de Estatuto de Autonomía de la Comunidad Valenciana. Este precepto se ocupa de los aprovechamientos hidráulicos y el fallo del Tribunal fue desestimar el recurso. 
En lo referente a los derechos sociales y los principios rectores, el Tribunal señala que se proyectan "sobre las competencias normativas de las Comunidades Autónomas porque van dirigidos a todos los poderes públicos sin excepción con el alcance y eficacia que les otorga el artículo 53.3 de la Constitución». Creemos en este punto más acertada la opinión del Tribunal aunque entendemos que sería de todo punto innecesario reiterar los principios rectores o derechos sociales en todos los Estatutos de Autonomía. Se reconocen en la Constitución y, efectivamente, inciden en el ámbito competencial por lo que su aparición en el listado de competencias de las Comunidades bastaría para realizar el correspondiente desarrollo legislativo.

En esta misma línea, se ha manifestado parte de la doctrina. RIPOLLÉS señala que "los derechos constitucionales lo son de todos los ciudadanos y las personas, por lo que no procede la regulación autonómica diferenciada de unos supuestos derechos que, si lo son, estarían en franca controversia con la legitimidad para determinar tales, que solo corresponde al órgano de manifestación del poder constituyente constituido, y, si no lo son, como parece lo más posible, sino facultades más que propiamente derechos, o, a lo sumo, derechos del administrado, no tienen porqué denominarse "derechos" con la consiguiente confusión a que puede conducir y las falsas expectativas jurídicas que puede generar" (68).

Otros creen que la inclusión de un Título relativo a derechos en los Estatutos no plantea dudas acerca de su inconstitucionalidad, entendiendo que es un aspecto positivo de los nuevos Estatutos, "en cuanto incluye elementos de integración simbólica y de orientación de la actividad de los poderes públicos autonómicos a los que estos preceptos vinculan» (69).

En esta misma línea se manifiesta VIVER I PI-SUNYER al señalar que la incorporación de los derechos en los Estatutos tiene tres limitaciones: «en primer lugar, debe respetarse la reserva de Ley orgánica del artículo 81.1 de la Constitución; en segundo lugar, esos derechos estatutarios y sus desarrollos y aplicación deben respetar las condiciones básicas que el Estado haya establecido para garantizar la igualdad en el ejercicio de los derechos fundamentales (artículo 149.1.1 de la Constitución) y, finalmente, el Estatuto debe ser coherente con la función constitucionalmente atribuida al Estatuto en tanto que norma institucional básica de la comunidad autónoma, es decir, en tanto que norma dirigida primordialmente a los poderes públicos» (70).

(68) RIPOLLÉS SERRANO, M. ${ }^{a}$ R., "La reforma de los Estatutos de Autonomía», Revista General de Derecho Constitucional, iustel.com, núm. 1, 2006, p. 3.

(69) BALAGUER CALLEJÓN, GARCÍA ROCA, MEDINA GUERRERO y SAIZ ARNAIZ, Conclusiones generales del Dictamen sobre la propuesta de reforma del Estatuto de Catalunya, de 24 de octubre de 2005.

(70) VIVER I PI-SUNYER, C., La reforma de los Estatutos de Autonomía, Madrid, 2005, pp. 31 y 32. 
Es cierto que, en su caso, el contenido de la parte dogmática en los Estatutos no puede suponer una alteración ni modificación de los derechos fundamentales y las libertades públicas que se recogen en la Constitución, puesto que competencialmente es el Estado el único que puede regular derechos que estén incluidos en la Carta Magna como fundamentales, y que por ello tienen reserva de Ley Orgánica, como ya hemos ido señalando. Igualmente es competencia estatal, y esto es esencial en el ámbito de los derechos, "la regulación de las condiciones básicas que garanticen la igualdad de todos los españoles en el ejercicio de los derechos y en el cumplimiento de los deberes constitucionales" como señala el artículo 149.1.1. ${ }^{a}$ de la Constitución (71). La incorporación de derechos que han realizado los Estatutos de Autonomía reformados recientemente se refieren por ello a los derechos de naturaleza social, derechos que en nuestra Constitución se recogen en el Capítulo $3 .^{\circ}$ delTítulo I como «Principios rectores de la política social y económica" y que como tales están dirigidos a la actuación de los poderes públicos, estatales y autonómicos. Dentro de este modelo, los poderes públicos deben asumir el compromiso de intervenir para hacer efectivos los valores superiores y garantizar la provisión de bienes sociales, dotando de recursos y prestaciones, con el objeto de asegurar los derechos sociales de las personas.

También se han incorporado a los Estatutos derechos no contemplados en la Constitución, cuyo establecimiento se deriva de un determinado título competencial autonómico. En esta línea se recogen en los nuevos Estatutos, bajo la forma de derechos, algunos de naturaleza social como los de acceso a una vivienda digna, los derechos y deberes en relación a los dependientes, el derecho al medio ambiente o los derechos sanitarios.

\section{Conclusiones: las reformas de los Estatutos ¿reforma constitucional encubierta?}

La descentralización del Estado Español, iniciada en el proceso pre- constituyente embarcó a los poderes públicos y a la ciudadanía en una aventura que involucró a los poderes centrales y pre-autonómicos. Se trataba, como ya hemos señalado, de implantar un nuevo modelo territorial de Estado, a medio camino entre el Estado federal y el centralizado. La aprobación de los Estatutos se convirtió, pues así lo previó la Constitución, en el instrumento jurídico de creación de las Comunidades Autónomas y, en pocos años el primer mapa autonómico quedó concluido. La Constitución y la voluntad de los actores políticos y de los ciudadanos fueron las guías que dirigieron el

(71) Vid., en este sentido, la crítica que realiza PORRAS RAMÍREZ, J. M., Las reformas estatutarias y el nuevo sistema de fuentes autonómico del Derecho, Madrid, 2007, pp. 23 a 33. 
proceso. No se produjeron conflictos insalvables y la distribución de competencias entre Estado y Comunidades se formalizó sin sobresaltos.

Muchas veces se ha señalado que hoy el contenido del Título VIII de la Constitución está agotado en la mayoría de sus previsiones. El anteproyecto de Constitución contemplaba un único tipo de Estatuto y un mismo esquema organizativo para todas las Comunidades Autónomas. Fue durante el proceso constituyente, sobre todo por los trabajos de la Comisión Constitucional del Congreso, cuando se configuraron los dos grandes grupos de Comunidades, las de régimen común y las de régimen especial.

En este marco se justifica el silencio del artículo 152 de la Constitución acerca de la organización institucional de las autonomías de régimen común, ya que se entendía que éstas gozarían exclusivamente de órganos de naturaleza administrativa. Esta intención de los constituyentes resultó políticamente inviable, puesto que, fue considerada discriminatoria, lo que obligó a entender que el silencio del artículo 152 de la Constitución debería interpretarse en el sentido de que las autonomías de régimen común podrían optar libremente por la estructura organizativa descrita en dicho precepto o por otra que en su momento se decidiera. Una vez aceptada esta interpretación por los Pactos Autonómicos de 1981, el resultado fue que el esquema del artículo 152 de la Constitución ha sido adoptado con carácter general por todas las Comunidades Autónomas. Tomando como referencia el contenido de los Estatutos, las Comunidades han desarrollado su régimen institucional mediante los Reglamentos parlamentarios y las Leyes del Gobierno y de la Administración. Ciertamente a partir de ese momento las similitudes son muchas, todas ellas tendentes a aproximar el modelo autonómico al estatal (72).

La existencia de hechos diferenciales en las Comunidades Autónomas sólo nos aporta un dato de carácter sociológico que adquiere magnitud si se pretende convertir en diferenciación con relevancia jurídica, pues esto nos aparta de la consecución del principio de solidaridad. Lamentablemente, estamos asistiendo a un "predominio de la bilateralidad como forma habitual de entender y configurar las relaciones entre el Estado y las Comunidades Autónomas» con el grave peligro de fragmentación (73). Evidentemente además de todo esto hay también una tensión competencial que supone que nuestro Estado de las Autonomías «adolece de ciertas carencias, al menos en tres aspectos importan-

(72) Así lo señala LÓPEZ GUERRA, L., "La organización de las Comunidades Autónomas», en LÓPEZ GUERRA, L. y otros, Derecho Constitucional (Vol. II), Valencia 2000, pp. 346 y 7.

(73) CONTRERAS CASADO, M., op. cit., p. 28. En esta misma línea el autor pone como ejemplo la aparición del "problema del agua» en los nuevos Estatutos reformados señalando "el Ebro, el Guadalquivir, el Tajo o el Duero, como oscuros objetos del deseo para cada una de las Comunidades que creen tener derechos preferenciales o competencias exclusivas sobre el agua que por ellas discurre». 
tes: "la coordinación, la cooperación y la integración» (74) y lo que en nuestra opinión es muy importante, pues los tres aspectos forman parte de la idea de unidad constitucional. Entendemos por esta unidad constitucional que el ordenamiento sea único evitándose las distorsiones en el trato a las personas en las distintas partes del territorio del Estado.

Es evidente que esta situación, que supone un camino a una mayor descentralización, podría culminar con una "solución auténticamente federal, con reconocimiento de la plurinacionalidad del Estado, una Cámara de representación territorial con potestades de esta índole, un Tribunal Constitucional de designación equitativa entre las nacionalidades y los órganos centrales" y "unas Constituciones de los Estados miembros que ellos mismos pudieran reformar respetando las directrices de la Constitución federal común» (75).

Con la aprobación de los nuevos Estatutos de Autonomía el problema que se presenta es grave. La generalización de la inclusión de derechos en los Estatutos podría ser discutible, pues como todos sabemos los derechos se proclaman en la Constitución, que ampara a todos los españoles, y en la correspondiente legislación de desarrollo. No obstante, la profundización en el proceso descentralizador al que está sometido nuestro Estado podría admitir que determinados derechos se recogieran en el texto estatutario, aunque sólo fuera como expresión del compromiso de los poderes autonómicos con la protección de los derechos de naturaleza social. Sin embargo, la proliferación de dichas declaraciones en los Estatutos ha ido modulando un elenco de derechos de distinta naturaleza que supuestamente deberían ser desarrollados mediante las correspondientes Leyes autonómicas.

En principio, no parecen apuntar razones que pongan en entredicho la constitucionalidad de estas inclusiones de derechos en los Estatutos. Las dudas se plantean porque la legislación autonómica abarca progresivamente nuevas facetas de los derechos de los ciudadanos, lo que en ocasiones está produciendo efectos jurídicos incómodos. Esto es, la expansión de la legislación autonómica sobre derechos, puede desencadenar un conglomerado falto de unidad, que desemboque en una verdadera vulneración de artículo 139 de la Constitución, al que ya nos hemos referido. En contra del espíritu y de la letra de la Constitución se produciría la desigualdad en el disfrute de los derechos de los españoles, quizá el elemento más importante de los que derivan del principio de unidad, proclamado en artículo 2, reforzado en otros preceptos constitucionales y vinculado a la dignidad de la persona según se formula en el artículo 10 de la Constitución.

(74) ARAGÓN, M., "La construcción del Estado Autonómico», Revista General de Derecho Constitucional, iustel.com, núm. 1, junio 2006, p. 16.

(75) LÓPEZ MIRA, A. X., «Veinticinco años del Estado Autonómico: una mala solución organizativa para un problema político", Revista de Derecho Político, UNED, núm. 58-59, 2003-2004, p. 747. 
Y, todo ello, dejando al margen que las Leyes autonómicas están regulando con insistencia aspectos más o menos relevantes de los derechos fundamentales y de las libertades públicas, puesto que la línea que separa los derechos por su naturaleza no es clara.Y en aras de la regulación de servicios que competen a las Comunidades autónomas, se incluyen aspectos sobre el honor, la intimidad o la propia imagen de los menores, o de las personas mayores o sobre sus derechos de expresión y reunión... Debemos tener en cuenta que se trata de derechos especialmente protegidos por el constituyente, aquellos que transformaron a la población española en ciudadanos iguales y libres, quedando abolidas las distinciones de cualquier naturaleza.

El sometimiento a la Constitución que impone el artículo 9.1 del texto exige que el legislador autonómico respete las Leyes Orgánicas que desarrollen estos derechos, incluso aunque no pretenda abordar el contenido esencial del derecho. Porque, como vimos, la Ley Orgánica puede regular exclusivamente el contenido esencial del derecho u optar por una regulación más completa del derecho, teniendo en cuenta además que el concepto de "contenido esencial», que señala el artículo 53.1 de la Constitución, es un concepto indeterminado, que en Tribunal Constitucional deberá definir en caso de una supuesta inconstitucionalidad. Por todo ello, el principio de seguridad jurídica aconseja prudencia en la expansión normativa autonómica, para evitar que una materia tan importante como son los derechos fundamentales y las libertades públicas, regulada en diferentes Leyes, reciba interpretaciones distintas, incluso en el supuesto de que el contenido sea semejante.

Llegados a este punto, "deshacer los pasos dados va a ser muy complicado" (76), pues en cualquier caso hora sería ya de afrontar una reforma constitucional. Numerosas voces se han alzado para proponer la reforma del Texto constitucional y no sólo para modificar el Título VIII. La cuestión es que creemos «contrario al principio de oportunidad cambiar preceptos constitucionales, aún cuando sus objetivos se justifiquen por razones de interés general y mejora del sistema, sin un proyecto de conjunto que enfoque soluciones reales de largo plazo» (77).

(76) FERNÁNDEZ FARRERES, G., op. cit., p. 168.

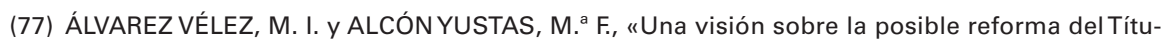
lo VIII de la Constitución Española de 1978", Anuario Parlamento y Constitución, núm. 8, 2004, p. 49. 
LABURPENA: Estatu espainiarraren deszentralizazioa, konstituzioaren prozesuaz bat abiatutakoa, Estatuaren lurralde-eredu berriaren abiapuntua izan zen, estatu federalaren eta estatu zentralizatuaren erdi-bidean kokatutako eredu berria.

Estatutuen onarpena autonomia-erkidegoak osatzeko tresna juridiko bilakatu zen eta, urte gutxiren buruan, prest zegoen jada lehenengo mapa autonomikoa. 2006. urtetik aurrera, Autonomia Estatutu berriak onartu zirenetik aurrera, eskumenen arazoa larriago egin zen, gizartearen eskubideak esaten zaien eskubideak berengain hartu dituztelako autonomia-erkidegoek, alegia, konstituzioak agintzen duen estatu sozialaren proiekzioa diren eskubideak. Ikerlan honetan, eskubide horiek estatutuetan sartzea orokortu izanak ekarritako arazoak aztertuko ditu, eztabaidarako bidea ematen du-eta. Onargarria izan daiteke zenbait eskubide estatutuaren testuan sartzea, botere autonomikoek izaera sozialeko eskubideak babesteko hartu duten konpromisoaren erakusgarri besterik ez bada ere. Nolanahi, halako adierazpenak gero eta gehiagotan sartzen dira estatutuetan eta bakoitzari dagozkion lege autonomikoen bitartez garatu beharreko omen diren honelako eta halako eskubideen sorta handia sortu da.

HITZ GAKOAK: Konstituzioa. Autonomia-estatutuak. Eskubideak eta askatasunak. Eskumenen banaketa.

RESUMEN: La descentralización del Estado Español, iniciada en el proceso constituyente supuso la implantación de un nuevo modelo territorial de Estado, a medio camino entre el Estado federal y el centralizado.

La aprobación de los Estatutos se convirtió en el instrumento jurídico de creación de las Comunidades Autónomas y, en pocos años, el primer mapa autonómico quedó concluido. A partir de 2006 con la aprobación de los nuevos Estatutos de Autonomía el problema competencial que se presenta es grave, pues las Comunidades Autónomas han asumido como competencias el desarrollo de los derechos denominados sociales y que suponen una proyección del Estado social que se propugna constitucionalmente. En el presente estudio se analiza la problemática acerca de la generalización de la inclusión de esos derechos en los Estatutos, pues podría ser cuestión discutible. Cierto es que se podría admitir que determinados derechos se recogieran en el texto estatutario, aunque sólo fuera como expresión del compromiso de los poderes autonómicos con la protección de los derechos de naturaleza social. Sin embargo, la proliferación de dichas declaraciones en los Estatutos ha ido modulando un elenco de derechos de distinta naturaleza que supuestamente deberían ser desarrollados mediante las correspondientes Leyes autonómicas.

PALABRAS CLAVE: Constitución. Estatutos de Autonomía. Derechos y libertades. Reparto competencial.

ABSTRACT: The descentralization of Spain which began in the constituant process meant a new territorial model of State, in-between a federal State and a centralized one. The passage of Statutes became a legal instrument for the 
foundation of the Autonomous Communities and in no time the first autonomic map was done. After 2006, with the passage of new Statutes of Autonomy, the problems around the allocation of powers came up as serious, since the Autonomous Communities have assumed the power to develop the so-called social rights and that meant a projection of the constitutionally advocated Social State. This present study analyzes the problems regarding the general inclusion of theses rights within Statutes, because it might be debatable. It is true that some rights could get included into the Statutes textes even if as expression of the commitmment by the Autonomic bodies with the protection of rights with social nature. Nevertheless, the proliferation of the mentioned bills of rights within the Statutes has modulated a cast of rights with different nature which should allegedly be developed by means of the corresponding autonomic acts.

KEYWORDS: Constitution. Autonomous Communities. Rights and freedoms. Allocation of powers. 